\title{
Análise sensorial e determinação da composição química nutricional de biscoito tipo cookie para autistas
}

\author{
Sensory Analysis and determination of the nutritional chemical composition of cookie-type \\ cookies for autistic
}

Análisis sensorial y determinación de la composición química nutricional de galletas tipo cookie para autistas

Maria Luiza Pereira dos Reis ${ }^{1 *}$, Ana Paula Araújo Silva ${ }^{1}$, Klelma Teixeira da Cunha ${ }^{1}$, Keila Cristiane Batista Bezerra ${ }^{1}$, Charllyton Luis Sena da Costa ${ }^{1}$, Marta Maria Fernandes de Vasconcelos ${ }^{2}$.

\section{RESUMO}

Objetivo: Esta pesquisa teve como objetivo a elaboração de um biscoito tipo cookie para autista, verificando sua aceitabilidade e composição nutricional. Método: Trata-se de um estudo experimental descritivo com abordagem qualitativa e quantitativa, realizada de setembro a outubro de 2017. Os dados foram coletados por meio da análise sensorial do biscoito, que foi realizada com 52 autistas de uma instituição de ensino voltada para inclusão de pessoas com deficiência. Os participantes foram informados sobre a formulação do produto e a técnica de aplicação da escala hedônica de expressões faciais. Os biscoitos foram elaborados sem glúten e sem caseína e posteriormente analisados quanto à composição química nutricional, segundo os parâmetros do Instituto Adolfo Lutz. Resultado: A análise sensorial apontou 52,1\% de aceitação. Em relação à composição centesimal, os resultados foram $7,88 \%$ de umidade, $7,90 \%$ de cinzas, $12,64 \%$ de lipídeo, proteína $9,41 \%$ e carboidrato por diferença $62,16 \%$. Conclusão: O biscoito obteve aceitação aprazível por parte das crianças e adolescentes autistas e apresentou qualidade nutricional adequada, macronutricionalmente falando.

Palavras-Chave: Formulação, Glúten, Caseína, Autista.

\section{ABSTRACT}

Objective: The aim of this research was to elaborate a cookie-type biscuit for autistic, verifying its acceptability and nutritional composition. Method: This is a descriptive experimental study with a qualitative and quantitative approach, carried out from September to October 2017. The data were collected through the sensory analysis of the biscuit, which was held with 52 autistic students from a teaching institution focused on the inclusion of disabled's. The participants were informed about the formulation of the product and the technique of applying the hedonic scale of facial expressions. The biscuits were prepared without gluten and without casein and subsequently analyzed for the nutritional chemical composition, according to the parameters of Adolfo Lutz Institute. Results: Sensory analysis showed $52.1 \%$ of acceptance. Regarding the centesimal composition, the results were $7.88 \%$ moisture, $7.90 \%$ ash, $12.64 \%$ lipid, $9.41 \%$ protein and carbohydrate by difference $62.16 \%$. Conclusion: The biscuit was pleasantly accepted by autistic children and adolescents and presented adequate nutritional quality, macro nutritionally speaking.

Keywords: Formulation, Gluten, Casein, Autistic.

\footnotetext{
${ }^{1}$ Centro Universitário Santo Agostinho - UNIFSA, Teresina - PI. *E-mail: marialuizanutri@outlook.com

${ }^{2}$ Centro Integrado de Educação Especial - CIES, Teresina - PI.
}

SUBMETIDO EM: 4/2019

ACEITO EM: 5/2019

PUBLICADO EM: 7/2019 


\section{RESUMEN}

Objetivo: Este estudio tiene como objetivo la elaboración de una galleta tipo cookie para autista, verificando su aceptabilidad y composición nutricional. Método: Se trata de una investigación experimental descriptiva de abordaje cualitativo y cuantitativo, realizada en septiembre hasta octubre de 2017. Se recogieron los datos a través del análisis sensorial de la galleta, realizado en 52 autistas de un centro de enseñanza de inclusión de personas con deficiencias. Los partícipes fueron informados de la formulación del producto y la técnica de aplicación de la escala hedónica de expresiones faciales. Las galletas han sido desarrolladas sin gluten y caseína, posteriormente analizada su composición química nutricional, según los parámetros del centro Adolfo Lutz. Resultados: El análisis sensorial apunta el 52,1\% de aprobación. Respecto a la composición centesimal, los resultados indicaron un 7,88\% de humedad, un 7,90\% de cenizas, un $12,64 \%$ de lípidos, proteína un 9,41\% y carbohidrato por diferenciación un 62,16\%. Conclusión: La galleta obtuvo una gran aceptabilidad por parte de los niños y adolescentes autistas y presentó cualidad nutricional adecuada, macronutricionalmente hablando.

Palabras Clave: Formulación, Gluten, Desarrollo, Caseína.

\section{INTRODUÇÃO}

O transtorno do espectro autista (TEA) pode ser considerado como uma síndrome, distúrbio ou transtorno neurológico, no qual é evidenciado por deficiência no convívio social, na conduta, na comunicação ocasionando um isolamento em um mundo próprio provocando desequilíbrio no desenvolvimento, onde suas manifestações são provavelmente identificadas por volta dos três primeiros anos de vida (BORGES ML e GOMES RS, 2016).

Sua causa é desconhecida, mas entre os transtornos neuropsiquiátricos é visto com maior interação aos fatores genéticos. Vale ressaltar que o autismo é mais comum no sexo masculino e seu diagnóstico é realizado através da observação da criança por meio do emprego de critérios específicos incluindo a retirada do glúten e caseína, uma vez que pesquisas mostram que determinados peptídeos presente nos alimentos pode ser propicio na determinação dos efeitos maléficos no sistema nervoso central por intermédio da comunicação com neurotransmissores (SILVA NI, 2011).

A maturidade intestinal é essencial na evolução cognitiva da criança, dessa maneira o comprometimento desse sistema pode suscitar complicações como, a possibilidade de toxidades, sendo essa uma das relevantes razões no aparecimento de distúrbios neurais (LEAL M, et al., 2015).

Os quadros gastrointestinais que eles comumente apresentam são: diarreia, constipação, vômitos, disbiose, doença inflamatória intestinal, entre outros, essas patologias e sintomas são decorrentes de uma desregulação da resposta do sistema imunológico ao trato gastrointestinal do autista (WOICIECHOSKI CG, 2013).

Verificações sobre a conduta alimentar das crianças com TEA exibem inadequações tais como: seletividade, simpatia com os alimentos conforme a textura, rejeição alimentar e comportamento de desordem durante as refeições. A multiplicidade limitada e o consumo inapropriado podem causar ingesta de calorias e nutrientes deficientes (TSCHINKEL PFS, 2014).

Em virtude do surgimento de carências nutricionais no portador do TEA, a indústria alimentícia tem investido na análise sensorial bem como na composição química nutricional de novos produtos alimentícios para autistas com a finalidade de suprir e atender esses déficits (BESSA ME, 2014).

Alguns estudos trazem evidências de que além dos distúrbios neurocomportamentais e sensoriais ocorrem alterações gastrointestinais. Deste modo os produtos alimentícios foram desenvolvidos com o intuito de incorporá-los a dieta do autista como uma opção para a melhoria do estado nutricional, mantendo a integridade intestinal na melhoria do nível de absorção de nutrientes através da retirada do glúten e da caseína (BESSA ME, 2014). 
Logo a análise sensorial é de extrema importância uma vez que a mesma é responsável por verificar a aceitabilidade de produtos desenvolvidos pela indústria alimentícia. Buscando o aperfeiçoamento da peculiaridade do produto final, garantindo sua estabilidade no mercado por meio do escopo de atender as exigências do público consumidor e priorizando sempre a qualidade e suas características organolépticas (MACAGNAN FT, et al., 2014).

Diante disso, este trabalho teve como objetivo desenvolver um biscoito tipo cookie, como uma opção saudável para dietas de crianças e adolescentes autistas, analisar sua aceitabilidade e composição química nutricional.

\section{MÉTODOS}

Trata-se de um estudo experimental descritivo com abordagem qualitativa e quantitativa. Após a aprovação pelo Comitê de Ética e Pesquisa sob o CAAE 69072517.4.0000.5602. O estudo foi executado com 52 autistas de ambos os sexos que frequentam uma instituição de ensino voltada para inclusão de pessoas com deficiências em idade escolar entre 5 e 14 anos de idade. Para a execução do teste afetivo, foram distribuídas fichas com a escala hedônica de expressões faciais com cinco categorias: 1 "Detestei"; 2 "Não Gostei"; 3 "Indiferente"; 4 "Gostei"; 5 "Adorei” (Figura 1). A amostra foi composta por estudantes autistas cujos representantes legais assinaram o Termo de Consentimento Livre e Esclarecido (TCLE).

Figura 1 - Figura da escala hedônica de expressões faciais.

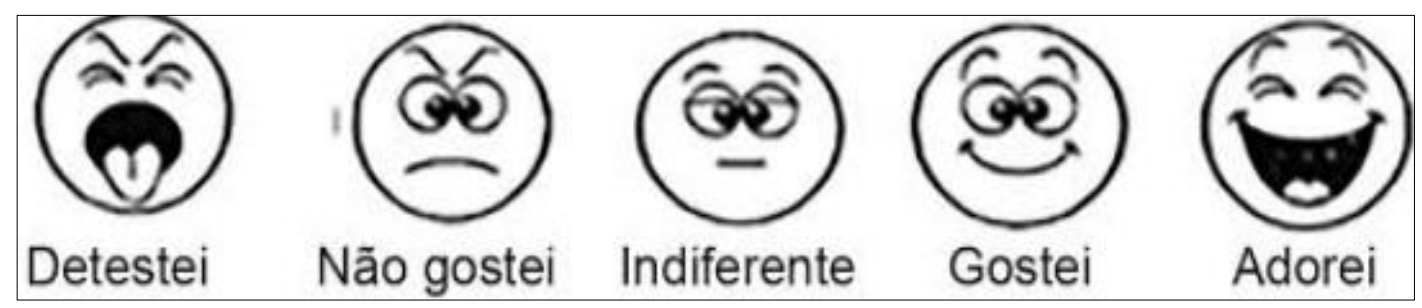

Fonte: Alves E et al. (2015).

\section{Fluxograma de Preparo}

Figura 2 - Fluxograma de produção da formulação do biscoito tipo cookie, 2017.

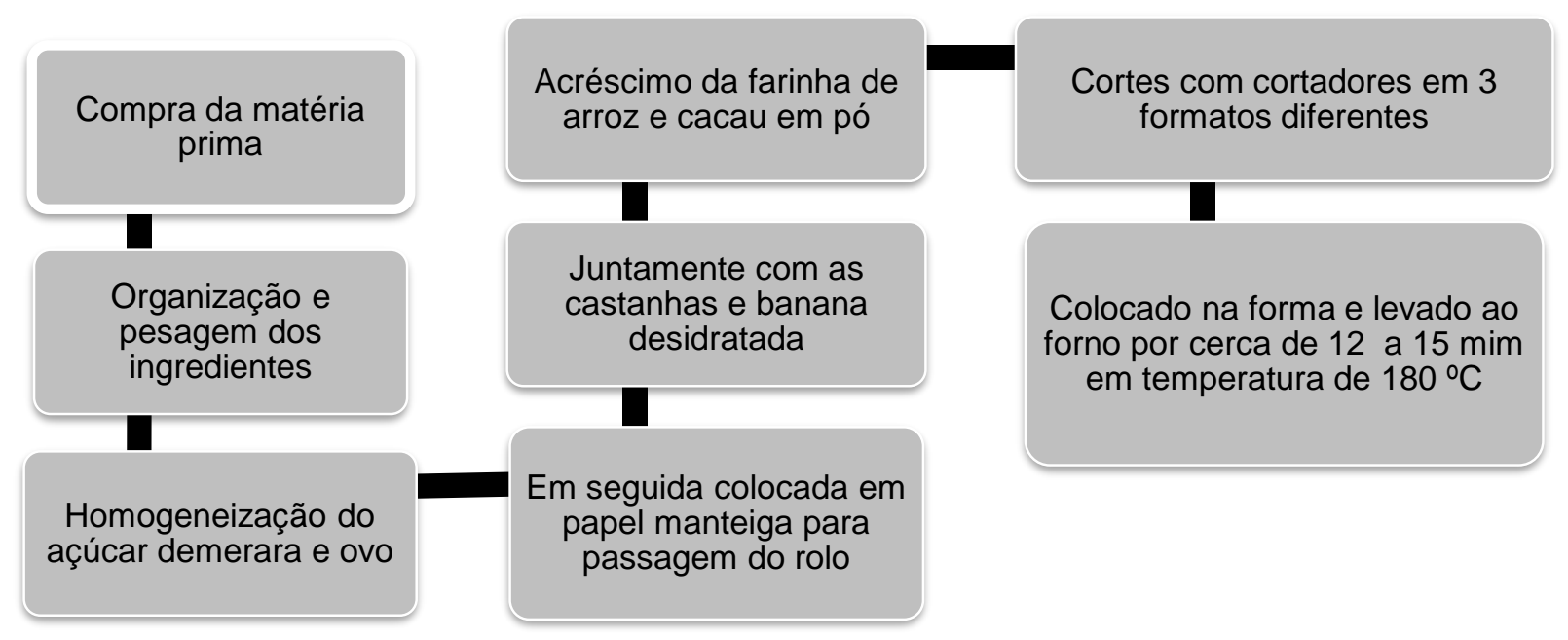

Fonte: Dados da Pesquisa, 2017. 


\section{Material}

A princípio selecionou-se uma receita padrão de biscoitos tipo "cookie" para servir como base para uma nova formulação com ingredientes específicos (Figura 2). No produto foram utilizados elementos substitutos ao trigo, como a farinha de arroz, e enriquecidos com castanha de caju, castanha do Pará, banana desidratada, ovo, açúcar demerara e cacau em pó (Tabela 1), por conseguinte, a massa foi fragmentada em tamanhos uniformes contendo $10 \mathrm{~g}$ cada, o rendimento para essa quantidade de ingredientes é de 156 biscoitos tipo cookie. A formulação foi elaborada no laboratório de Técnica e Dietética do Centro Universitário Santo Agostinho - UNIFSA.

Tabela 1 - Ingredientes que foram utilizados na formulação do biscoito tipo cookie e suas respectivas medidas caseiras. Teresina - PI, 2017.

\begin{tabular}{llll}
\hline \multicolumn{4}{l}{ Ingredientes da formulação } \\
\hline Ingredientes & Medida Caseira & $\mathrm{g}$ & $\%$ \\
Farinha de Arroz & 2 xícaras de nivelada & 268 & 34,4 \\
Açúcar Demerara & $1 / 2$ xícara & 100 & 12,8 \\
Cacau em Pó & 1 xícara de chá & 84 & 10,8 \\
Banana Desidratada & $1^{1 / 2}$ xícara de chá & 120 & 15,4 \\
Castanha de Caju & 15 unidades trituradas & 37,5 & 6,1 \\
Castanha do Pará & 12 unidades trituradas & 40 & 4,8 \\
Ovos & 2 unidades & 120 & 15,4 \\
\hline
\end{tabular}

Fonte: Dados da Pesquisa, 2017.

\section{Composição centesimal}

Para determinação da umidade utilizou-se o método de secagem por meio de uma balança que possui acoplada uma fonte de radiação infravermelha, procedimento denominado "Unidade de secagem Mettler LTJ" (Mettler, Brasil) ajustando-se a intensidade da radiação emitida de modo que a amostra atingisse $105{ }^{\circ} \mathrm{C}$. Para a realização da análise a massa inicial registrada foi de $5 \mathrm{~g}$, e posicionou-se a radiação sobre a amostra, posteriormente a massa final (peso constante) foi registrada.

Segundo Lutz IA (2008); a análise química centesimal é caracterizada pela composição de um alimento que descreve a quantidade de nutrientes presentes nestes. É possível a partir da composição, investigar a riqueza do alimento em alguns grupos homogêneos apontados. Vale salientar que as análises foram realizadas em triplicata.

A determinação do conteúdo mineral foi realizada por meio da incineração do produto em mufla aproximadamente a uma temperatura de $550 \stackrel{\circ}{\mathrm{C}}$, utilizando $5 \mathrm{~g}$ da amostra do biscoito tipo cookie. Os lipídeos foram extraídos em aparelho Soxhlet, utilizando hexano como solvente. As proteínas foram determinadas pelo método de Kjeldahl, utilizando o valor de 6,25 como fator de conversão em proteína bruta. Os carboidratos foram determinados por diferença.

\section{Análises dos Resultados}

Os dados foram analisados quantitativamente pelo programa Microsoft Excel 14.0 para a construção das tabelas, expressa na forma de estatística descritiva obtendo a distribuição de frequência da aceitabilidade do biscoito, por meio de médias e desvio padrão.

\section{RESULTADO E DISCUSSÃO}

\section{Teste de aceitabilidade}

Realizou-se o teste para avaliar a aceitabilidade do biscoito tipo cookie por meio da escala hedônica de expressões faciais. Os pais e responsáveis pelas crianças e adolescentes receberam três amostras do 
biscoito contendo $10 \mathrm{~g}$ cada e esclarecimentos sobre a pesquisa, onde foram informados sobre os riscos e benefícios do estudo. A tabela 2 mostra a aplicação de um teste de aceitação com 52 provadores autistas.

As expressões faciais da escala hedônica receberam notas de acordo com o nível de aceitabilidade pelos autistas sendo detestei 1 e adorei 5. Calculou-se a nota média do biscoito desenvolvido, que foi de aproximadamente 3,2 , valor esse encontrado após realizar a média aritmética das notas obtidas. De acordo com os resultados foi possível analisar que a formulação do biscoito tipo cookie foi bem aceita pelos portadores do transtorno do espectro autista, pois dentre as expressões faciais analisadas pelas crianças e adolescentes nas fichas testes, as opções gostei representa $(32,8 \%)$ e adorei $(19,3 \%)$ foram de maior prevalência, somando-se um total de $52,1 \%$ de aceitação.

Em trabalho semelhante, Borges ML e Gomes RS (2016); desenvolveram bolinhos para autistas, com substituição da farinha de trigo. O teste foi realizado com 90 provadores sadios utilizando a escala hedônica estruturada de 9 pontos. Após a aplicação do teste os mesmos obtiveram um resultado positivo, com grande aceitação das amostras. As formulações da farinha de arroz (FA) e amido resistente concentrado de milho (HM) foram as mais aceitas no teste da escala hedônica.

Tabela 2 - Percentual de aceitação da análise sensorial do biscoito tipo cookie para autistas, Teresina- PI 2017.

\begin{tabular}{lccc}
\hline Ficha Teste & Classificação & $\mathbf{N}$ & $\%$ \\
\hline Detestei & 1 & 10 & 19,3 \\
Não Gostei & 2 & 05 & 9,3 \\
Indiferente & 3 & 10 & 19,3 \\
Gostei & 4 & 17 & 32,8 \\
Adorei & 5 & 10 & 19,3 \\
Total de Amostras & ---- & 52 & 100 \\
\hline
\end{tabular}

Fonte: Dados da Pesquisa, 2017.

Legenda: ---- ausência.

Outras pesquisas obtiveram resultados parecidos com alimentos similares aos testados no presente estudo, Aranha DC et al. (2017); relatou em seu estudo que o percentual de aceitação global do biscoito tipo 'cookie' funcional foi de $100 \%$ e que não houve nenhum atributo negativo quanto à aceitação global do biscoito.

A aceitação do biscoito tipo cookie para autistas representa um importante fator para propiciar uma melhor qualidade de vida, uma vez que os autistas apresentam comportamento específico e com interesses diminutos a alimentação.

Segundo Nunes MRA et al. (2016); em seu estudo descreveram que autistas são muito seletivos e resistentes ao novo, criando bloqueio a novas experiências alimentares que não sejam benéficas ou interessantes, visto que o comportamento monótono leva a formação de hábito alimentar e o interesse restrito pode ter função significativa na seletividade dietética.

\section{Composição centesimal}

As análises químicas foram realizadas em triplicata no laboratório de Bromatologia e no Centro de Tecnologia em Alimentos do Serviço Nacional de Aprendizagem Industrial - SENAI. A composição química dos biscoitos foi determinada segundo as normas descritas pelo Instituto Adolfo Lutz (2008). Os dados referentes à composição centesimal encontram-se exibidos na tabela 3.

O valor nutritivo da formulação do biscoito tipo cookie foi obtido a partir da realização da composição centesimal dos macronutrientes analisados. Tal particularidade é de ampla importância se levarmos em conta os déficits nutricionais dos indivíduos com TEA, uma vez, que a ingestão de nutrientes é inapropriada. Além desses aspectos macro nutricionais referente aos valores encontrados de lipídeo, carboidrato e proteína na tabela abaixo, é importante ressaltar que o teor de umidade identificado representa a estabilidade do 
armazenamento do biscoito por um maior espaço de tempo. No tocante as cinzas representam o resíduo inorgânico, ou seja, trata-se do ponto de partida para a análise de minerais específicos analisados para fins nutricionais que venham a tentar diminuir as carências apresentadas pelo público em questão.

Tabela 3 - Composição centesimal e valor energético do biscoito tipo cookie para Autista, Teresina -PI 2017.

\begin{tabular}{llll}
\hline Composição & Formulação $(\mathbf{g})$ & Máximo & Mínimo \\
\hline Umidade & $7,88 \pm 0,93$ & 9,55 & 6,51 \\
Cinza & $7,90 \pm 0,86$ & 8,40 & 7,40 \\
Lipídeo & $12,64 \pm 0,93$ & 13,21 & 11,92 \\
Proteína & $9,41 \pm 0,26$ & 9,63 & 9,31 \\
Carboidrato & 62,16 & ---- & --- \\
\hline
\end{tabular}

Fonte: Dados da Pesquisa.

Legenda: Resultado das análises com média realizada em triplicata ( \pm desvio padrão).

*carboidratos por diferença; subtraindo-se de 100 os valores obtidos para umidade, cinza, lipídeo, proteína.

A umidade de um alimento está relacionada com sua estabilidade, qualidade e composição. A baixa umidade de 7,88\% encontrada no biscoito representa elevada vida de prateleira, elevando as chances de inibir o crescimento de microrganismos, apresenta menores riscos em relação a problemas na conservação, dessa forma os pais terão facilidade em armazenar o biscoito. De acordo com a Resolução RDC ํㅡ 263, de 22 de setembro de (2005) da Agência Nacional de Vigilância Sanitária - ANVISA, a umidade de biscoitos deve ser no máximo de $14 \%$, portanto os valores de umidade da formulação encontram-se de acordo com a legislação.

Mariani M, et al.; (2015). elaboraram um biscoito semelhante com a adição de farinha arroz, farelo de arroz e farinha de soja, e a umidade dos biscoitos foi similar a este estudo $7.20 \%$. Em um trabalho equivalente Vieira TS, et al.; (2015). que produziu um biscoito sem glúten, encontrou valor de umidade superior a este estudo com 13,39\%, e apesar de se encontrar dentro do parâmetro da legislação esse maior conteúdo de umidade no biscoito pode favorecer as reações enzimáticas de deterioração.

Em alimentos, as cinzas são consideradas resíduos inorgânicas remanescentes da queima da matéria orgânica, sem resíduo de carvão, a cinza de um material é o ponto de partida para a análise de minerais específicos.

Estes minerais são analisados tanto para fins nutricionais como também para segurança. $O$ teor de resíduo mineral fixo foi determinado por incineração do material em mufla regulada a $550{ }^{\circ} \mathrm{C}$. O biscoito tipo cookie apresenta um teor de cinza significativo $7,90 \%$, o que pode contribuir de forma positiva para indivíduos portadores de TEA.

Em um estudo realizado por Klein AL, et al. (2015); notou-se que uma das amostras analisada, obteve um valor de cinza um pouco menor em relação ao biscoito tipo cookie que girou em torno de $5.18 \%$. Cleirici MTPS, et al. (2013); produziram biscoito tipo cookie com farinha desengordurada de gergelim constataram teor de cinza de $5.15 \%$.

Queiroz AM et al. (2017); elaborou cookies sem glúten enriquecido com farinha de coco, observou-se que o teor de cinza encontrando variou de $0,84 \%$ a $0,96 \%$, no entanto os valores descobertos não acarretaram aumento relevante com relação ao teor de cinza, quando confrontados com a formulação padrão.

A substância lipídica nos alimentos pode alterar conforme os componentes utilizados. No que diz respeito ao teor de lipídeos, a formulação conteve valor de 12,64\%, mostrando assim teor expressivo que pode contribuir de forma benéfica para as crianças e adolescentes com transtorno do espectro autista.

Pereira MM et al. (2016); elaboraram e avaliaram as características físico-químicas de biscoitos amanteigados de farinha de jatobá e constataram uma variação de $13,70 \%$ (padrão) a 16,24\% (F3) valores esses superior ao encontrando no vigente estudo. 
Em relação ao conteúdo proteico o biscoito apresentou percentual considerável de 9,41\%, esses dados corroboram com o estudo de Silva RR, et al. (2014); no qual se observou que ao desenvolver um biscoito tipo cookie com amêndoa de pequi o teor de proteína encontrado de $9,89 \%$ é similar ao do biscoito desenvolvido para os portadores de TEA.

Em outro estudo Mariani M, et al. (2015); no qual fabricam biscoitos sem glúten a partir de farelo de arroz, farinhas de arroz e de soja, foi possível analisar que em relação ao conteúdo proteico, houve diferença estatística significativa entre si $(p<0,05)$. O biscoito de farelo de arroz + farinha de soja - FEFS apresentou maior teor proteico $(14,22 \%)$, seguido dos biscoitos farinha de arroz + farinha de soja - FAFS $(11,96 \%)$, estando estas quantidades proteicas superiores aos achados nesta pesquisa.

Pode-se observar que o biscoito tipo cookie é rico em carboidrato com $62,16 \%$, sendo esses provenientes da farinha de arroz e do açúcar demerara, esse macronutriente é de extrema importância, uma vez que fornece energia para o organismo e especialmente para cérebro. No trabalho de Erkel A et al. (2015); foi possível verificar que as quantidades de carboidrato presente nas 4 formulações de biscoito tipo cookie a base de farinha da casca do abacaxi obteve média equivalente $63,15 \%$, esse resultado indica, de um modo geral, valores próximos quando comparamos com esta pesquisa. Padia MLB (2018); ao elaborar cookie funcional com bagaço de malte com concentrações diferentes (F1): $25 \%$ e (F2) $50 \%$ de bagaço de malte, obteve valores de carboidratos de $53,35 \%$ e $42,10 \%$ respectivamente, sendo esses teores menores que os obtidos nesse estudo.

\section{CONCLUSÃO}

Observou-se que após a realização da análise sensorial os biscoitos apresentaram boa aceitabilidade pelos autistas. Uma vez que durante a elaboração da formulação levou-se em consideração as deficiências nutricionais do público em questão, trazendo assim uma opção de produto ao mercado para suprir os déficits que os portadores de TEA possuem. Visto que problemas gastrointestinais são constantes em indivíduos autistas e as desordens metabólicas podem carrear a necessidades aumentadas de minerais e vitaminas, consequentemente uma melhor oferta de macronutriente e micronutriente podem levar a melhora da sintomatologia. Após a realização das análises foi constatado que o biscoito tem pouca umidade, consequentemente maior vida de prateleira, além disso, apresentou uma quantidade considerável de cinza, ou seja, conteúdo mineral fixo. Os resultados deste trabalho revelam taxa de conteúdo proteico relevante, além de evidenciar a formulação do biscoito tipo cookie como opção para dietas de autistas, com adição de farinha de arroz, oleaginosas e exclusão do glúten e caseína, apresentam maiores teores de lipídeos e carboidratos. Portanto, a formulação buscou promover a melhoria do estado nutricional de indivíduos portadores do Transtorno do Espectro Autista.

\section{REFERÊNCIAS}

1. Agência Nacional de Vigilância Sanitária. RDC 263: regulamento técnico para produtos de cereais, amidos, farinhas e farelos - elaboração. Brasília, 2005.6f.

2. ARANHA DC, et al. Avaliação sensorial de biscoito tipo "cookie" funcional e enriquecido em proteínas. Ling. Acadêmica, 2017; 7(5): 23-34.

3. ALVES E, et al. Avaliação da composição nutricional e da aceitabilidade da merenda oferecida na rede municipal de ensino da cidade de Maringá - PR. Enciclopédia Biosfera, 2015; 11(22).

4. BESSA ME. Percepção sensorial e aceitação do leite de cabra fermentado. Dissertação (Mestrado em Ciência e Tecnologia do Leite e Derivados, área de concentração: Qualidade do Leite e Derivados) - Universidade Federal de Juiz de Fora, Juiz de Fora, 2014; 121 p.

5. BORGES ML, GOMES RS. Desenvolvimento e avaliação sensorial de bolinhos, para autistas, com substituição da farinha de trigo. Monografia (Bacharelado em Nutrição) - Universidade Federal Fluminense, Niterói, 2016; 51p.

6. CLERICI MTPS, et al. Qualidade física, química e sensorial de biscoitos tipo cookies elaborados com a substituição parcial da farinha de trigo por farinha desengordurada de gergelim. Brazilian Journal of Food Technology, 2013; 6(2). 
7. ERKEL A, et al. Utilização da Farinha de Casca de Abacaxi em Cookies: Caracterização Físico-Química e Aceitabilidade Sensorial entre Crianças. Revista Uniabeu Belford Roxo, 2015; 8(19).

8. INSTITUTO ADOLFO LUTZ. Normas analíticas do instituto Adolfo Lutz. Métodos físico-químicos para análise de alimentos. São Paulo; 2008. p. 1020,

9. KLEIN AL. Características físico-químicas de biscoitos comerciais do tipo cookies adquiridos no vale do taquari. Revista Destaque Acadêmicos, 2015; 7(4).

10. LEAL M, et al. Terapia nutricional em crianças com transtorno do espectro autista. Cad. Da Escola de Saúde. 2015; 1(13): $1-13$.

11. MACAGNAN FT. et al. Caracterização nutricional e resposta sensorial de pães de mel com alto teor de fibra alimentar elaborados com farinhas de subprodutos do processamento de frutas. B. Ceppa, 2014; 32(2): 201 -210.

12. MARIANI M, et al. Elaboração e avaliação de biscoitos sem glúten a partir de farelo de arroz e farinhas de arroz $e$ de soja. Revista Braz. J. Food Technol. 2015; 18(1): 70-78.

13. NUNES MRA, et al. Educação inclusiva: uso de cartilha com considerações sobre a alimentação do autista. Revista Includere, 2016; 2:114- 118.

14. PADIA ML B. Cookie funcional com bagaço de malte uma nova proposta quando comparado ao industrializado. Monografia (Bacharelado em Nutrição) - Universidade Regional do Noroeste do Rio Grande do Sul, ljuí, $2018 ; 62$ p.

15. PEREIRA MM, et al. Processamento e caracterização físico-química de biscoitos amanteigados elaborados com farinha de jatobá. Revista Brasileira de Tecnologia Agroindustrial, Ponta Grossa, 2016; 10(2): 2137-2149.

16. QUEIROZ AM, et al. Elaboração e caracterização de cookies sem glúten enriquecidos com farinha de coco: uma alternativa para celíacos. Revista BrazilianJournalofFood Technology, 2017; 2(2).

17. SILVA NI. Relação entre hábito alimentar e síndrome do espectro autista. Dissertação (Mestrado em Ciência e Tecnologia de Alimentos) - Universidade de São Paulo, Piracicaba, 2011; 135p.

18. SILVA RR, et al. Desenvolvimento de biscoitos tipos cookie formulados com amêndoa de pequi (Caryocar brasiliense Camb.) comparados com biscoito tipo cookie de chocolate. Revista Brasileira de Produtos Agroindustriais, 2014; 16(1): 77- 82.

19. TSCHINKEL PFS. Avaliação das concentrações plasmáticas dos elementos traço cobre, zinco e selênio em crianças com transtorno do espectro autista. Dissertação (Mestrado apresentado ao programa de pós-graduação em saúde) - Universidade Federal de Mato Grosso do Sul, Campo Grande, 2014; 99p.

20. VIEIRA TS et al. Efeito da substituição da farinha de trigo no desenvolvimento de biscoitos sem glúten. Revista Braz J. Food Technol, 2015; 18(4): 285-292.

21. WOICIECHOSKI CG. Importância da retirada do glúten e da caseína na dieta de crianças portadoras do transtorno do espectro autista. Monografia (Bacharelado em Nutrição) - Centro Universitário de Brasília: UNICEUB, Brasília, $2013 ; 44 p$. 